\title{
Vogt-Koyanagi-Harada Syndrome following COVID-19 and ChAdOx1 nCoV-19 (AZD1222) vaccine
}

\author{
Janaína Jamile Ferreira Saraceno' ${ }^{1}$ Guilherme Macedo Souza², Luciana Peixoto dos Santos Finamor², \\ Heloisa Moraes Nascimento ${ }^{2,3^{*}}$ (D) and Rubens Belfort $\mathrm{Jr}^{2,3}$
}

\begin{abstract}
The challenge of COVID-19 has rapidly changed medical management worldwide. The relatively small time from pandemic to vaccines regulatory approval triggered a race toward vaccines development. However, important questions regarding SARS-CoV-2 vaccines remain. A case of complete Vogt-Koyanagi-Harada (VKH) Syndrome that occurred 4 days following SARS-CoV-2 vaccination and another patient that developed VKH 14 days post COVID-19 clinical onset are presented. A causal relationship between COVID-19 and uveitis may exist.
\end{abstract}

\section{Introduction}

Vogt-Koyanagi-Harada (VKH) syndrome is a multisystem disorder with chronic, bilateral, non-necrotizing, granulomatous panuveitis and exudative retinal detachment [1-5]. The etiology of VKH remains unknown, and the pathogenesis is thought to be multifactorial and primarily targets the choroidal layer. Many etiologies were previously reported, most of which were immunogenetic and environmental. It is a T-cell-mediated autoimmune response against one or more antigenic components of melanocytes [6-8].

Previous reports demonstrate VKH association with interferon-alpha, pembrolizumab and dabrafenib/ trametinib therapy, as well as after vaccination for influenza, yellow fever and BCG. Immunological mechanisms and dysregulation of the immune system may play a significant role in the association between VKH disease and COVID-19 [9-15].

Rare descriptions of post-COVID-19 immune-mediated conditions such as uveitis, Guillain-Barré syndrome

\footnotetext{
*Correspondence: helomn@gmail.com

2 Department of Ophthalmology and Visual Science, Federal University of Sao Paulo, Sao Paulo, Brazil
}

Full list of author information is available at the end of the article or systemic lupus erythematosus have been published. It is speculated that SARS-CoV-2 can disturb self-tolerance and trigger autoimmune responses through cross-reactivity with host cells [16-18].

A case of complete VKH that occurred 4 days following vaccination with ChAdOx1 nCoV-19 (AZD1222) and another patient that developed VKH 14 days post COVID-19 clinical onset are presented. To our knowledge, no previous reports have indicated that SARS$\mathrm{CoV}-2$ infection or the vaccine may be related to the $\mathrm{VKH}$.

\section{Cases reports \\ Patient 1}

A 62-year-old healthy female patient developed a severe headache and tinnitus 2 days after receiving COVID-19 immunization with the Oxford-AstraZeneca Chimpanzee Adenovirus Vectored Vaccine ChAdOx1 nCoV-19 (AZD1222). Two days later she developed an acute loss of vision in both eyes.

BCVA was 20/600 in OD and 20/200 in OS, IOP was $14 \mathrm{mmHg}$ OU and the slit-lamp examination showed a mild inflammation in the anterior chamber with $2+$ cells and $1+$ of vitreous cells OU. Fundus examination showed original author(s) and the source, provide a link to the Creative Commons licence, and indicate if changes were made. The images or other third party material in this article are included in the article's Creative Commons licence, unless indicated otherwise in a credit line to the material. If material is not included in the article's Creative Commons licence and your intended use is not permitted by statutory regulation or exceeds the permitted use, you will need to obtain permission directly from the copyright holder. To view a copy of this licence, visit http://creativecommons.org/licenses/by/4.0/. The Creative Commons Public Domain Dedication waiver (http://creativeco mmons.org/publicdomain/zero/1.0/) applies to the data made available in this article, unless otherwise stated in a credit line to the data. 
a serous retinal detachment and optic disc hyperemia OU (Fig. 1). OCT showed bilateral serous retinal detachment, bacillary layer detachment and subretinal hyperreflective dots (Fig. 2).

\section{Patient 2}

A 37-year-old female patient with a 15 days history of blurred vision with metamorphopsia in both eyes, associated with tinnitus and no prior history of eye trauma or intraocular surgery was seen. Two weeks before she had experienced headache, anosmia and fever and tested positive for the SARS COV-2 on rt-PCR test.

BCVA was hand motion in OU and intraocular pressure was normal. Slit-lamp examination showed granulomatous keratic precipitates (KP) in OD, and mild vitritis OU. Fundus examination showed serous retinal detachment with an inferior bullous detachment and optic disk hyperemia in OU (Fig. 3), fluorescein angiography revealed bilateral optic disk hyperfluorescence due to leakage and multiple hyperfluorescence pinpoints (Fig. 4), OCT revealed a bilateral serous retinal detachment with bacillary detachment (Fig. 5), characterizing initial onset.

In both cases, systemic evaluation was nonspecific with mononuclear cells in the cerebrospinal fluid and infectious work-up was negative. Both were diagnosed as

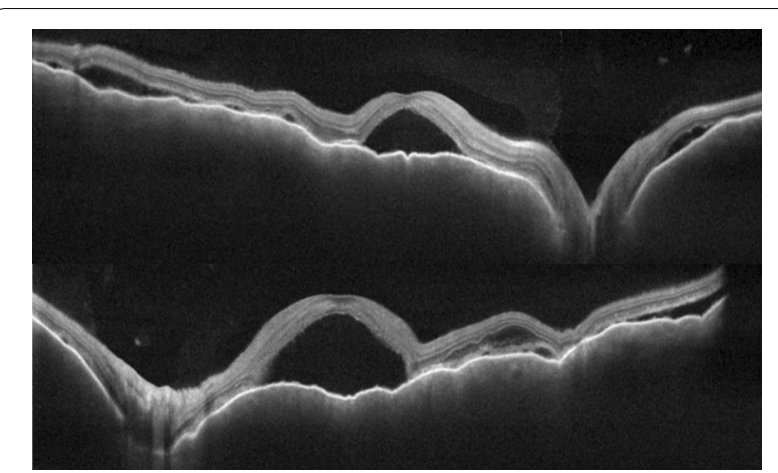

Fig. 2 (Patient 1) OCT of both eyes showing serous retinal detachment with bacillary layer detachment

complete VKH syndrome, according to the Revised Diagnostic Criteria (RDC) [3].

Patient 1 was treated with oral systemic prednisone $(1.5 \mathrm{mg} / \mathrm{kg} /$ day $)$ - intravenous therapy was avoided due to the severity of the pandemic at that time and the restriction of available hospital beds-and within 4 days the visual acuity improved to 20/60 OD and 20/80 OS. She continued to be followed up, using regressive oral corticosteroid therapy, and after 3 weeks, evolved with BCVA of 20/20 OU, no signs of inflammatory activity and disappearance of the retinal detachment (Figs. 6 and 7).

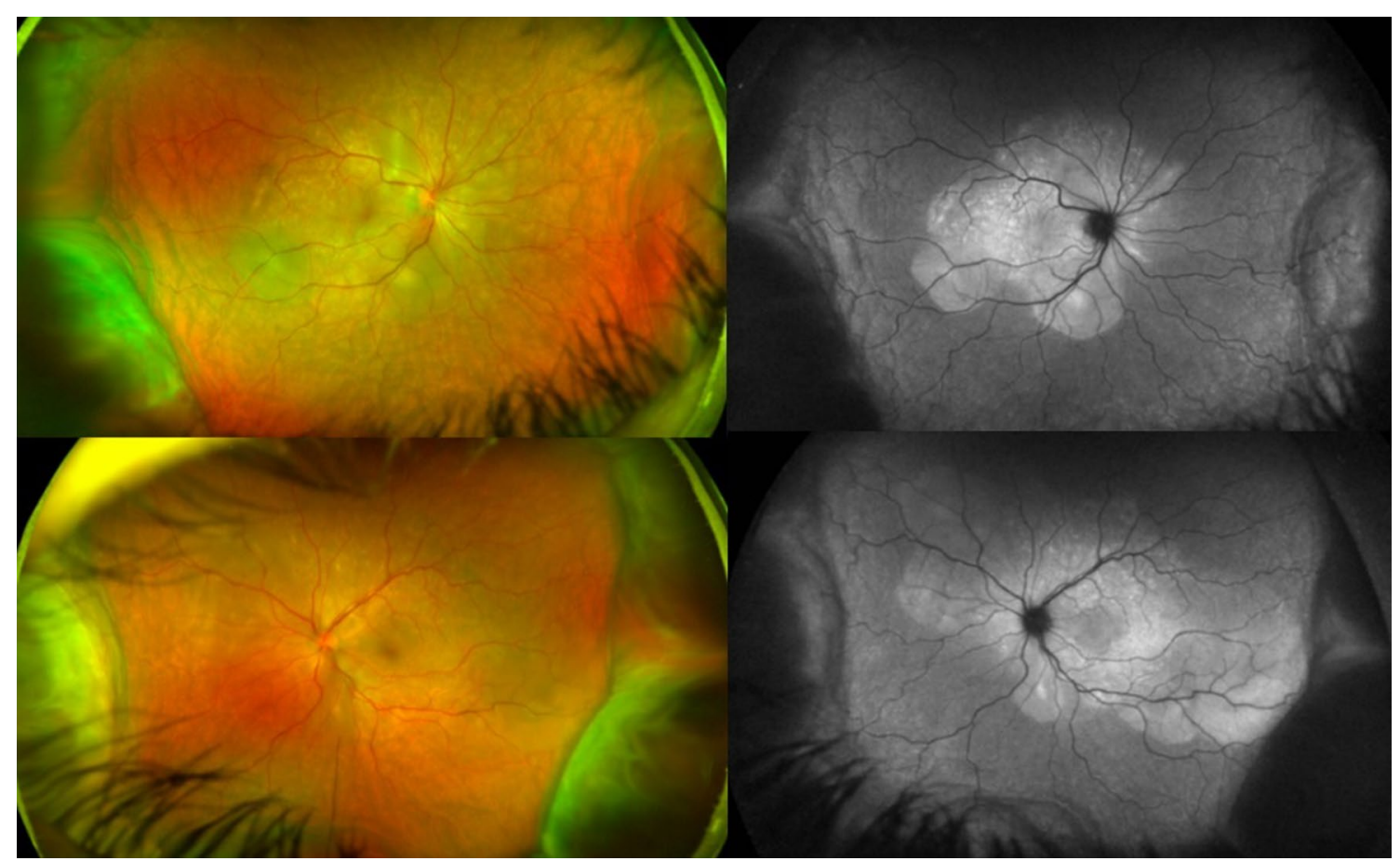

Fig. 1 (Patient 1) Fundoscopy and autofluorescence of both eyes showing serous retinal detachment and optic disc hyperemia 


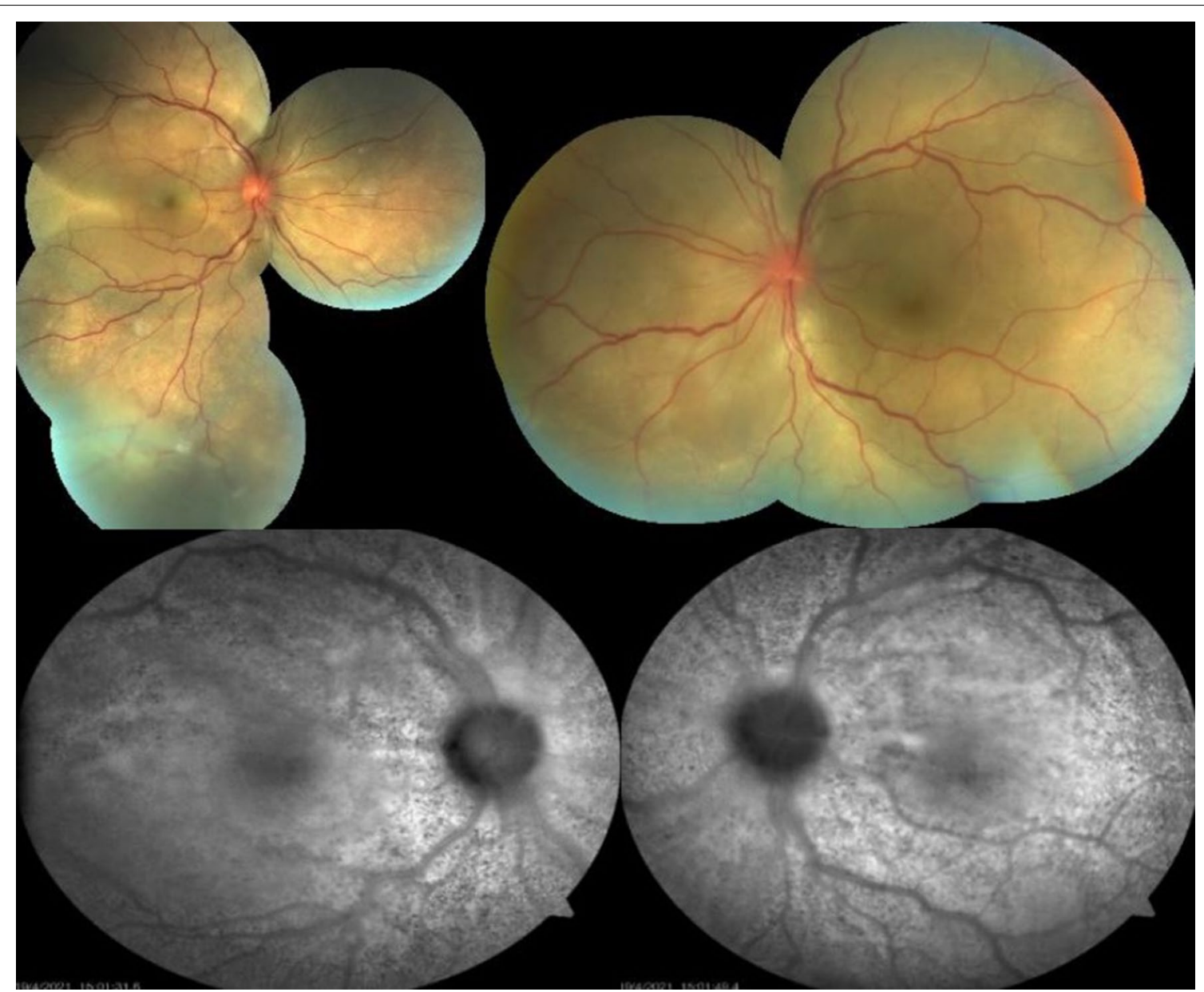

Fig. 3 (Patient 2) Fundoscopy and autofluorescence of both eyes showing serous retinal detachment, optic disc hyperemia and choroidal inflammation

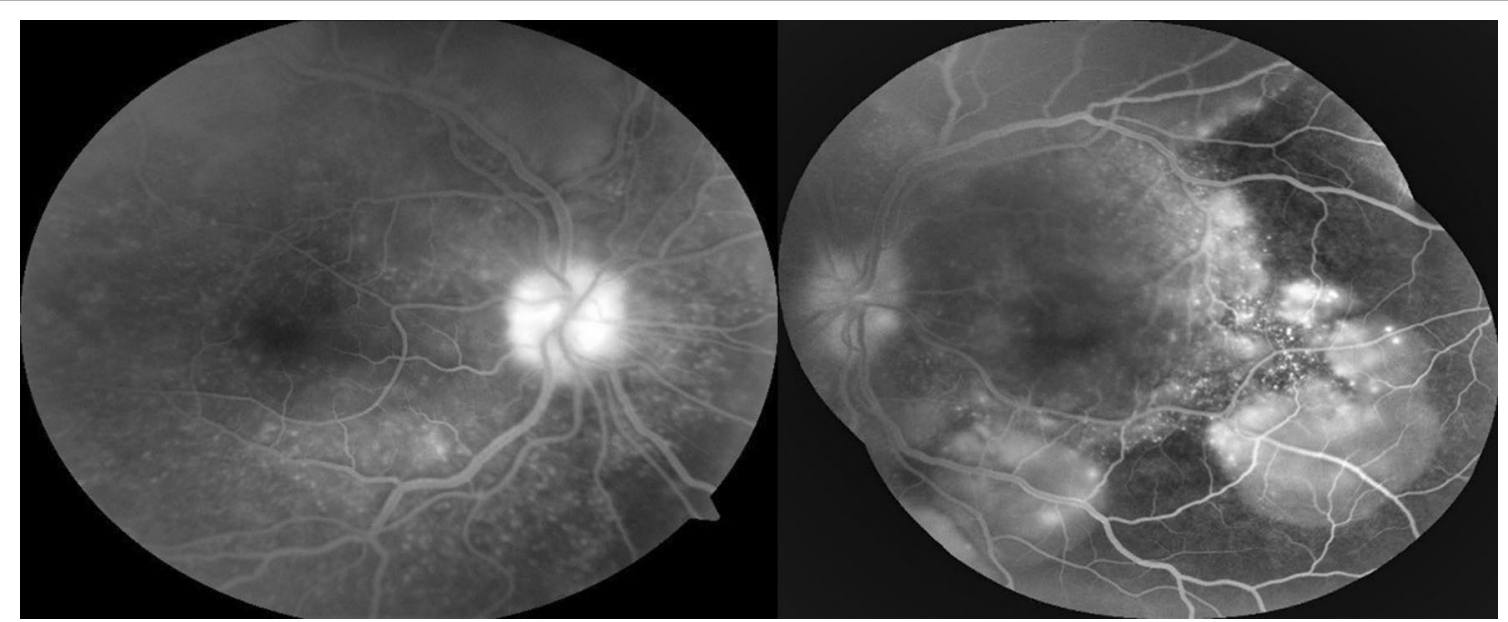

Fig. 4 (Patient 2) Fluorescein angiography of both eyes 


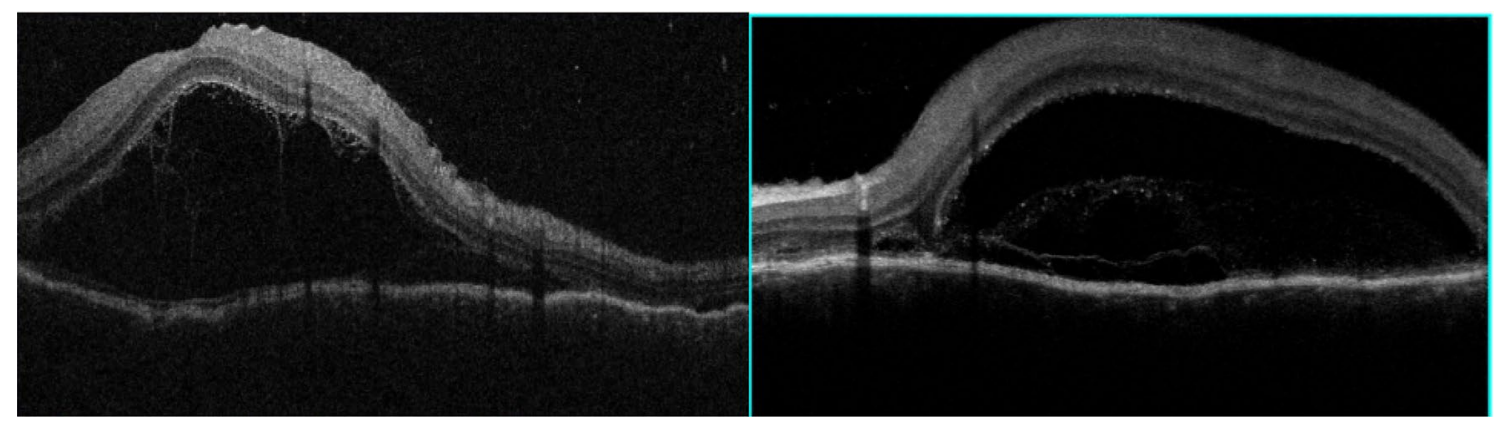

Fig. 5 (Patient 2) OCT of both eyes showing serous retinal detachment with bacillary layer detachment

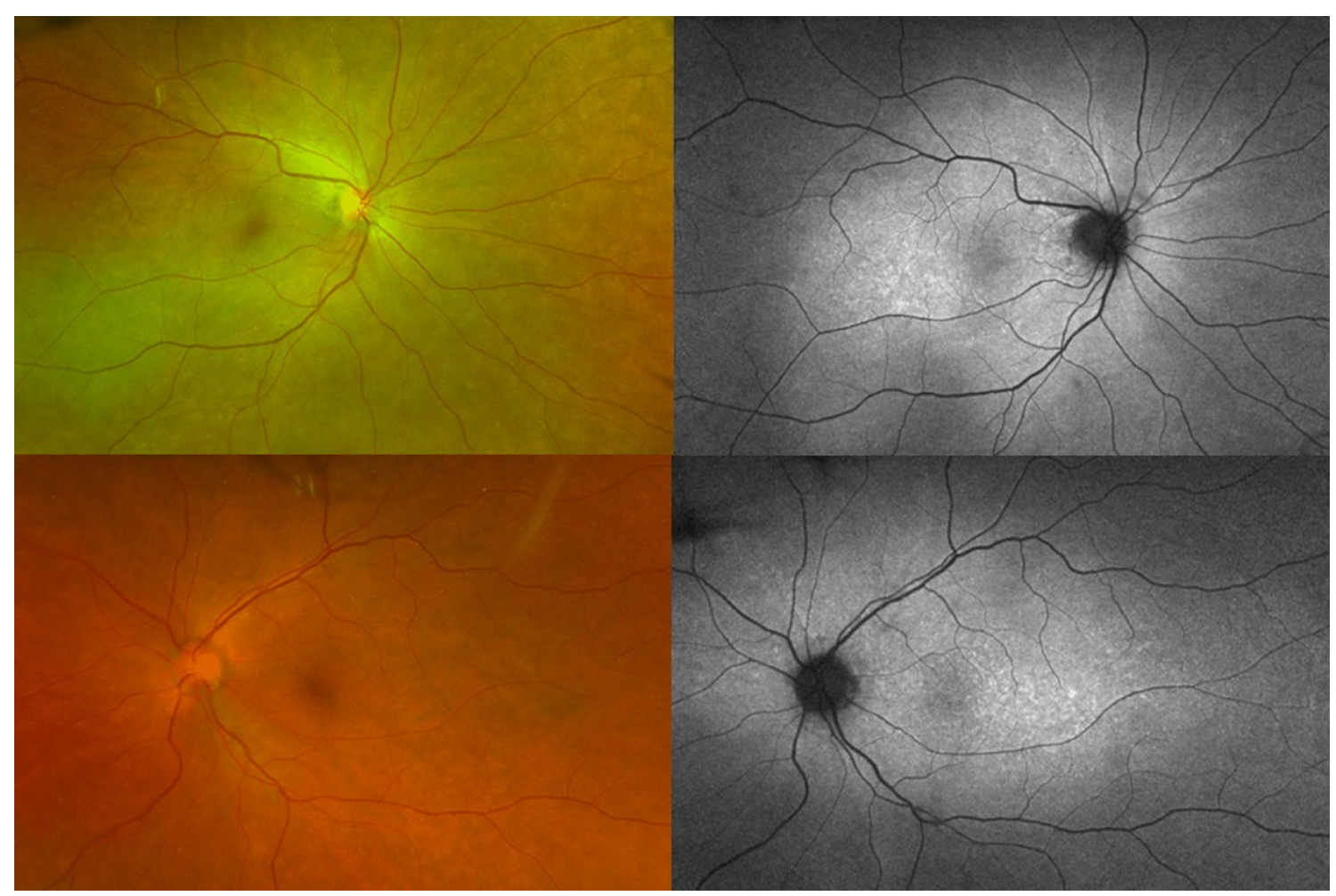

Fig. 6 (Patient 1) Fundoscopy and autofluorescence of both eyes showing improvement of the serous retinal detachment

Patient 2 was also treated with oral systemic prednisone $(1 \mathrm{mg} / \mathrm{kg} /$ day, dose was taped by $10 \mathrm{mg}$ every week). On the thirtieth treatment day her visual acuity achieved 20/25 OD and 20/50 OS, no signs of inflammatory activity and improvement of retinal detachment (Figs. 8 and 9).

Both patients have been followed up for the past 2 and 3 months respectively and have not had recurrence of the disease. Even with the COVID pandemic, these patients are being closely monitored due to the severity of the disease, with potential visual impairment.

\section{Discussion}

Vogt-Koyanagi-Harada is a bilateral, autoimmune diffuse granulomatous uveitis associated with neurological, audiovestibular, and dermatological abnormalities. Although the exact pathogenesis is still uncertain, immunological and histopathological studies suggest that $\mathrm{VKH}$ is mediated by $\mathrm{CD} 4+\mathrm{T}$ cells that target melanocytes. These activated $\mathrm{T}$ cells likely initiate the inflammatory process through generation of cytokines, IL-17 and IL23. Genetic factors and viral infections are likely involved [1-8]. 


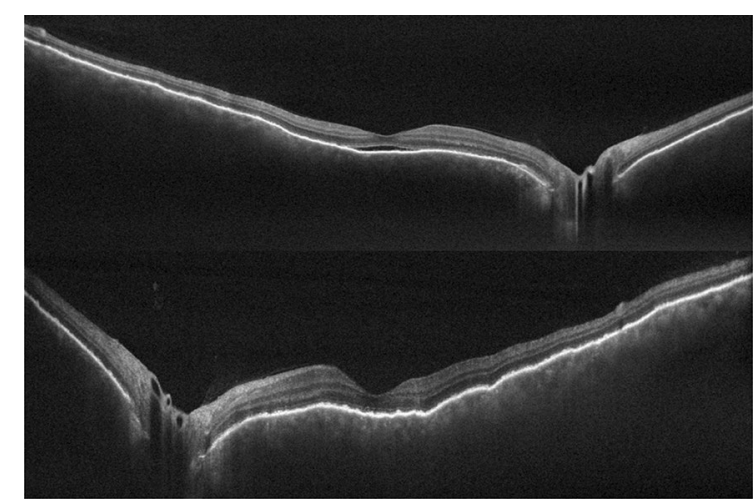

Fig. 7 (Patient 1) OCT of both eyes showing improvement of the serous retinal detachment and bacillary layer detachment
Viral diseases may play a role in VKH development, as CMV seroprevalence is higher in VKH patients, and cross-reaction between tyrosinase peptides and cytomegalovirus antigen by $\mathrm{T}$ cells from patients with $\mathrm{VKH}$ has already been stablished [8]. Other virus, as Influenza A, was described as a trigger to VHK in a positive for HLA-DR4 patient [9]. Wade and cols. described a case of a 14-year-old female, without evidence of active M. pneumoniae infection, presented with elevated antibody titers and signs of VKH disease [19].

Bilateral uveitis with extraocular changes that were virtually identical to VKH was described in three patients with Hepatitis $\mathrm{C}(\mathrm{HCV})$. Two of them manifested the uveitis after the initiation of pegylated interferon- $2 b$ treatment. It suggests a possible association between the $\mathrm{HCV}$ infection and/or treatment with interferon and the development of $\mathrm{VKH}$. The patients improved after

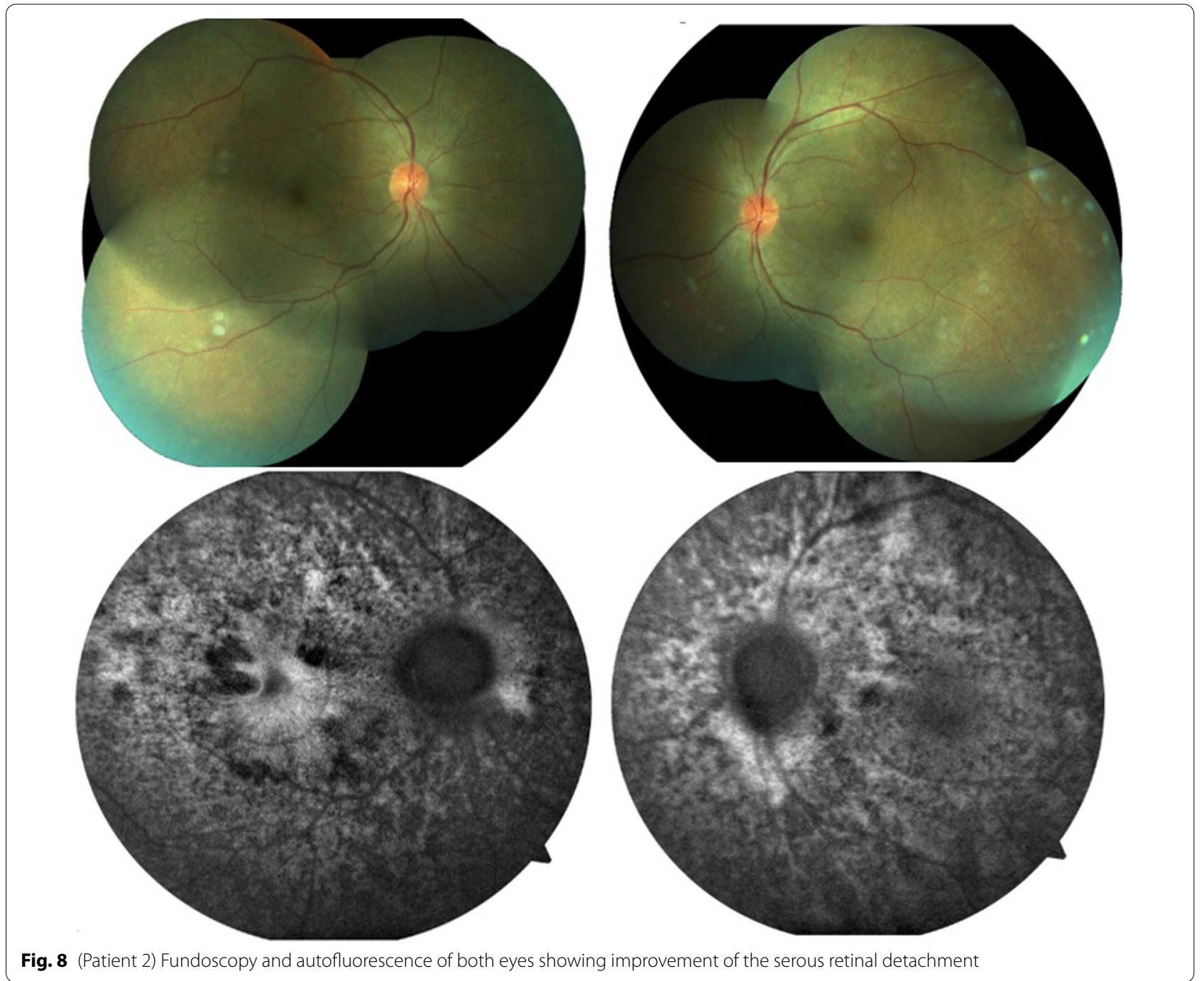



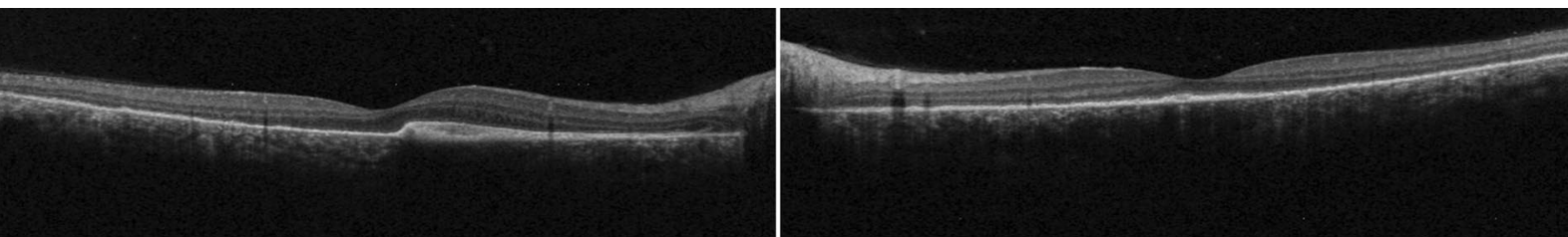

Fig. 9 (Patient 2) OCT of both eyes showing resolution of the serous retinal detachment and bacillary layer detachment

corticosteroids and immunosuppressive treatment and suspension of the antiviral therapy $[10,11]$.

VKH can also associate with systemic autoimmune diseases, such as autoimmune polyglandular syndrome, Guillain-Barré syndrome, and immunoglobulin A nephropathy [20, 21].

Dogan et al. described a case of VKH following BCG vaccination in a patient treating superficial transitional cell carcinoma (TCC) of the bladder, and another one with both VKH and tuberculosis. The authors speculated that M. tuberculosis and BCG proteins induce high Th1 responses causing uveitis by antigenic mimicry [13].

Reports described a case of VKH following influenza, hepatitis B and yellow fever vaccination. One proposed mechanism is related to the use of adjuvants in vaccines. Adjuvants enhance immunogenic activity by a combination of mechanisms, including cytokine and chemokine release, sustained release of antigen (depot effect), activation of antigen presenting cells, antibody production, and cellular recruitment. Adjuvants are also routinely used in experimental auto-immune uveitis models [9-15].

The Oxford-AstraZeneca ChAdOx1 nCoV-19 vaccine (AZD1222) consists in a replication-deficient adenoviral vector, containing the SARS-CoV-2 structural surface glycoprotein antigen gene, and there are no adjuvants used in its composition. This vaccine induces generation of binding and neutralizing antibodies, and interferon- $\gamma$ enzyme-linked immunospot responses [22]. Patel et al. describes a case of a 37-year-old man who was diagnosed with Guillain-Barre syndrome (GBS) 3 weeks post the first dose of the ChAdOx1 vaccine, in the absence of any other triggering factors. There are a few cases, which have been published correlating COVID-19 infection with the development of GBS [18].

Recently a case of Citokine Release Syndrome that occurred 5 days after vaccination with BTN162b2 (tozinameran)-the Pfizer-BioNTech mRNA COVID-19 vaccine-in a patient with colorectal cancer was reported [23].

Although it is difficult to determine causality, our cases raise the possibility of ChAdOx1 nCoV-19 (AZD1222) vaccination and COVID-19 triggering-or even causing$\mathrm{VKH}$ disease. This report of vaccine-induced VKH can enlighten possible causative mechanisms involved in $\mathrm{VKH}$ pathogenesis. Sir. Stewart Duke-Elder, in 1966, had already emphasized that the etiology of numerous obscure uveitis may be secondary to virus infections [24]. The possibility of identifying which Sars-CoV-2 viral particles-possible used in the vaccines, as the structural surface glycoprotein antigen-may trigger uveitis is an important path for scientific research.

\section{Acknowledgements}

Conselho Nacional de Desenvolvimento Científico e Tecnológico (CNPq) (1270963774537698); Coordenação de Aperfeiçoamento de Pessoal de Nível Superior (CAPES).

\section{Authors' contributions}

JJFS was the main writer of this paper and acquired data of the Patient 2; GMS was the second writer and acquired data of the Patient 1; LPSF was a reviewer and made substantial contributions to the conception of the paper; HMN was a reviewer, made substantial contributions to the conception of the paper and is the Corresponding Author; RBJ was a reviewer and made substantial contributions to the conception of the paper. All authors have approved the manuscript submission for publication. All authors read and approved the final manuscript.

\section{Funding}

Conselho Nacional de Desenvolvimento Científico e Tecnológico (CNPq); Coordenação de Aperfeiçoamento de Pessoal de Nível Superior (CAPES).

Availability of data and materials

All data generated during this study are included in this published article.

\section{Declarations}

\section{Ethics approval and consent to participate}

Ethical approval for this study was obtained from Invitare-Pesquisa Clínica Auditoria e Consultoria LTDA (CAAE: 30764320.6.0000.8098). Written informed consent was obtained from all subjects before the study.

\section{Consent for publication}

Written informed consent was obtained from all subjects before the study.

\section{Competing interests}

The authors declare that there is no conflict of interest regarding the publication of this paper.

\section{Author details}

'Department of Ophthalmology, Hospital Sao Rafael, Salvador, Brazil. ${ }^{2}$ Department of Ophthalmology and Visual Science, Federal University of Sao Paulo, Sao Paulo, Brazil. ${ }^{3}$ Research Department, Instituto Paulista de Estudos e Pesquisas em Oftalmologia/Instituto da Visão (IPEPO), Sao Paulo, Brazil.

Received: 25 June 2021 Accepted: 17 August 2021

Published online: 30 August 2021 


\section{References}

1. Greco A, Fusconi M, Gallo A, et al. Vogt-Koyanagi-Harada syndrome. Autoimmun Rev. 2013;12(11):1033-8.

2. O'Keefe GAD, Rao NA. Vogt-Koyanagi-Harada disease. Surv Ophthalmol. 2017:62(1):1-25.

3. Read RW, Holland GN, Rao NA, et al. Revised diagnostic criteria for Vogt-Koyanagi-Harada disease: report of an international committee on nomenclature. Am J Ophthalmol. 2001;131(5):647-52.

4. O'Keefe GA, Rao NA. Vogt-Koyanagi-Harada disease. Surv Ophthalmol. 2017;62(1):1-25. https://doi.org/10.1016/j.survophthal.2016.05.002 (Epub 2016 May 27)

5. Liu XY, Peng XY, Wang S, et al. Features of optical coherence tomography for the diagnosis of Vogt-Koyanagi-Harada disease. Retina. 2016;36(11):2116-23.

6. Chi W, Yang P, Li B, et al. IL-23 promotes CD4+ T cells to produce IL-17 in Vogt-Koyanagi-Harada disease. J Allergy Clin Immunol. 2007;119(5):1218-24.

7. Li F, Yang P, Liu X, Wang C, Hou S, Kijlstra A. Upregulation of interleukin 21 and promotion of interleukin 17 production in chronic or recurrent VogtKoyanagi-Harada disease. Arch Ophthalmol. 2010:128(11):1449-54.

8. Sugita S, Takase H, Kawaguchi T, et al. Cross-reaction between tyrosinase peptides and cytomegalovirus antigen by T cells from patients with VogtKoyanagi-Harada disease. Int Ophthalmol. 2007;27(2-3):87-95.

9. Yoshino N, Kawamura A, Ishii A, Yoshida K, Watanabe T, Yamashita T, Fukuchi T, Toyoda F, Kakehashi A, Sugawara H. Vogt-Koyanagi-Harada disease associated with influenza A virus infection. Intern Med. 2018;57(11):16615. https://doi.org/10.2169/internalmedicine.9819-17 (Epub 2018 Jan 11).

10. Duan J, Wang Y, Liu D, Ma J. Induction of Vogt-Koyanagi-Harada disease by interferon-alpha and ribavirin treatment in patients with hepatitis C: a case report and review of the literature. Ocul Immunol Inflamm. 2019:27(2):229-34. https://doi.org/10.1080/09273948.2017.1373827 (Epub 2017 Oct 12).

11. Touitou V, Bodaghi B, Cassoux N, Tran TH, Rao NA, Cacoub P, LeHoang P. Vogt-Koyanagi-Harada disease in patients with chronic hepatitis C. Am J Ophthalmol. 2005;140(5):949-52. https://doi.org/10.1016/j.ajo.2005.06 020.

12. Campos WR, Cenachi SPF, Soares MS, Gonçalves PF, Vasconcelos-Santos DV. Vogt-Koyanagi-Harada-like disease following yellow fever vaccination. Ocul Immunol Inflamm. 2021;29(1):124-7. https://doi.org/10.1080/09273 948.2019.1661498 (Epub 2019 Oct 11).

13. Dogan B, Erol MK, Cengiz A. Vogt-Koyanagi-Harada disease following BCG vaccination and tuberculosis. Springerplus. 2016;5:603. https://doi.org/10. 1186/s40064-016-2223-4
14. Kim M. Vogt-Koyanagi-Harada Syndrome following influenza vaccination. Indian J Ophthalmol. 2016;64(1):98. https://doi.org/10.4103/0301-4738. 178141.

15. Bricout M, Petre A, Amini-Adle M, Bezza W, Seve P, Kodjikian L, Dalle S, Thomas L. Vogt-Koyanagi-Harada-like syndrome complicating pembrolizumab treatment for metastatic melanoma. J Immunother. 2017;40(2):77-82. https://doi.org/10.1097/CJl.0000000000000154.

16. Meckiff BJ, Ramírez-Suástegui C, Fajardo V, Chee SJ, Kusnadi A, Simon H, Eschweiler S, Grifoni A, Pelosi E, Weiskopf D, Sette A, Ay F, Seumois G, Ottensmeier $\mathrm{CH}$, Vijayanand P. Imbalance of regulatory and cytotoxic SARS-CoV-2-reactive CD4 ${ }^{+}$T cells in COVID-19. Cell. 2020;183(5):13401353. https://doi.org/10.1016/j.cell.2020.10.001 (Epub 2020 Oct 5).

17. Liu Y, Sawalha AH, Lu Q. COVID-19 and autoimmune diseases. Curr Opin Rheumatol. 2021:33(2):155-62.

18. Patel SU, Khurram R, Lakhani A, Quirk B. Guillain-Barre syndrome following the first dose of the chimpanzee adenovirus-vectored COVID-19 vaccine, ChAdOx1. BMJ Case Rep. 2021;14(4): e242956. https://doi.org/10.1136/ bcr-2021-242956.

19. Wade Cl, Earley KE, Justin GA, Weber ML. Vogt-Koyanagi-Harada disease presenting secondary to a post-infectious Mycoplasma pneumoniae autoimmune response. Am J Ophthalmol Case Rep. 2020;22(19): 100793. https://doi.org/10.1016/j.ajoc.2020.100793.

20. Jovic N, Nesovic M, Vranjesevic D, et al. The Vogt- Koyanagi-Harada syndrome: association with autoimmune polyglandular syndrome type 1. Postgrad Med J. 1996;72(850):495-7.

21. Najman-Vainer J, Levinson RD, Graves MC, et al. An association between Vogt-Koyanagi-Harada disease and Guillain-Barré syndrome. Am J Ophthalmol. 2001;131(5):615-9.

22. Knoll MD, Wonodi C. Oxford-AstraZeneca COVID-19 vaccine efficacy. Lancet. 2021;397(10269):72-4. https://doi.org/10.1016/S0140-6736(20) 32623-4 (Epub 2020 Dec 8).

23. Au L,Turajlic S, et al. CAPTURE Consortium, Cytokine release syndrome in a patient with colorectal cancer after vaccination with BNT162b2. Nat Med. 2021. doi: https://doi.org/10.1038/s41591-021-01387-6. (Epub ahead of print).

24. Duke-Elder S, Perkins ES. Diseases of the uveal tract. System of ophthalmology, vol. 9. London: Henry Kimpton Publishers Ltd; 1966.

\section{Publisher's Note}

Springer Nature remains neutral with regard to jurisdictional claims in published maps and institutional affiliations.
Ready to submit your research? Choose BMC and benefit from:

- fast, convenient online submission

- thorough peer review by experienced researchers in your field

- rapid publication on acceptance

- support for research data, including large and complex data types

- gold Open Access which fosters wider collaboration and increased citations

- maximum visibility for your research: over 100M website views per year

At BMC, research is always in progress.

Learn more biomedcentral.com/submissions 